\title{
The Midas touch?
}

\author{
Peter A U Twiddy
}

Abstract

Objective-To test the hypothesis that GP trainees are worth their weight in gold.

Design-Data collected from 100 consecutive patients analysed with reference to practice statistics, fees, and allowances.

Setting-General practice, Edinburgh.

Results-In the year April 1992 to April 1993 the trainee saw 3439 patients, who were worth over $£ 18000$ in capitation fees. The training grant is $£ 4570$, the trainee performed child health surveillance worth $£ 1000$, and items of service fees earned more than $£ 8500$. The trainee brought over $£ 31000$ into the practice in one year.

Conclusion-Trainees are (almost) worth their weight in gold.

\section{Introduction}

Training practices receive many benefits but work under certain constraints. This study is concerned only with the financial aspects of training: the money brought into the practice by the trainee and the money spent by the practice on the trainee.

\section{Methods and results}

The practice population was broken down by age bands, and the consultation rate was calculated. I counted the number of patients seen by the trainee in a year and collated the items of service fees for 100 consecutive patients seen by the trainee. These data were used to produce figures for the whole year.

The trainer's grant is $£ 4750$ a year. Table I shows the age distribution of the practice population, capitation fees for each age group, and the product of the population fractions and the capitation fee. The sum of the final figures produces the "composite capitation fee" of $£ 15.60$. This represents the fee for the "average patient."

The practice consultation rate (the number of doctor-patient consultations per patient per year for the practice) was 2.95 . If the composite capitation fee is divided by the consultation rate the result is the money earned for each consultation; this is $£ 5.29$. The total number of patients seen by the trainee in the year was 3439 . The value of the practice capitation fees attributable to the trainee was $£ 18192.31$.

The present fee for child health surveillance is $£ 10.35$ each year and children are seen four times in five years for child health surveillance. Each check is therefore worth $£ 12.94$ to the practice. The trainee saw 75 children in child health surveillance clinics in a year, earning the practice $£ 970.50$.
TABLE I-Practice population, age breakdown, and capitation fees

\begin{tabular}{lccc}
\hline $\begin{array}{l}\text { Age range } \\
\text { (years) }\end{array}$ & $\begin{array}{c}\text { Fraction of } \\
\text { practice } \\
\text { population }\end{array}$ & $\begin{array}{c}\text { Standard } \\
\text { capitation } \\
\text { fee }\end{array}$ & $\begin{array}{c}\text { Fraction of } \\
\text { practice } x \\
\text { capitation fee }\end{array}$ \\
\hline$<65$ & 0.885 & $£ 14.16$ & 12.53 \\
$65-74$ & 0.062 & $£ 18.66$ & 1.15 \\
$\geqslant 75$ & 0.053 & $£ 36.09$ & 1.91 \\
\hline Total & & & 15.60 \\
\hline
\end{tabular}

TABLE II-Item of service fees

\begin{tabular}{|c|c|c|c|c|c|}
\hline Item of service & $\begin{array}{c}\text { Standard } \\
\text { fee }\end{array}$ & $\begin{array}{c}\text { Unit } \\
\text { fee }\end{array}$ & $\begin{array}{c}\begin{array}{c}\text { Units } \\
\text { in } \\
\text { study }\end{array} \\
\end{array}$ & $\begin{array}{c}\text { Units } \\
\text { in one } \\
\text { year }\end{array}$ & $\begin{array}{c}\text { Total fee } \\
\text { in one } \\
\text { year }(f)\end{array}$ \\
\hline Antenatal care & $89 \cdot 08$ & 8.908 & 2 & $68 \cdot 78$ & 612.69 \\
\hline Contraceptive services & $13 \cdot 25$ & $5 \cdot 30$ & 8 & $275 \cdot 12$ & 1458.14 \\
\hline \multicolumn{6}{|l|}{ Immunisation and } \\
\hline and vaccination & 3.45 & 3.45 & 2 & $68 \cdot 78$ & 237.29 \\
\hline Medical examination & $48 \cdot 50$ & $48 \cdot 50$ & 1 & $34 \cdot 39$ & 1667.91 \\
\hline Minor surgery & $103 \cdot 80$ & $20 \cdot 76$ & 3 & $103 \cdot 17$ & $1245.60^{\star}$ \\
\hline New patient check & $6 \cdot 30$ & $6 \cdot 30$ & 1 & $34 \cdot 39$ & 216.66 \\
\hline Night visit & $46 \cdot 65$ & $46 \cdot 65$ & 1 & $34 \cdot 39$ & 1604.29 \\
\hline Social work form & $14 \cdot 60$ & $14 \cdot 60$ & 1 & $34 \cdot 39$ & 502.09 \\
\hline Temporary resident & $8 \cdot 40 / 12 \cdot 60$ & $10 \cdot 50$ & 3 & $103 \cdot 17$ & 1083.29 \\
\hline
\end{tabular}

*This figure is smaller than expected by calculation but represents the maximum claim allowable in one year.

Table II shows the breakdown of items of service fees. The unit fee represents the money earned by the practice for each consultation in which an item of service fee can be claimed. For immunisation and vaccination, medical examination, new patient check, night visit, and social work form the unit fee equals the standard fee. For antenatal care it is estimated that each patient attends for 10 appointments from booking to delivery so the standard fee is divided by 10 to produce the unit fee. For contraceptive services it is estimated that each patient will attend 2.5 times a year so the standard fee is divided by 2.5 to produce the unit fee. Minor surgery fees are earned for blocks of five patients and therefore the standard fee is divided by 5 to produce the unit fee. Temporary resident fees are paid at two different levels depending on whether the patient is temporarily resident for more or less than 15 days. An average of the two levels has been calculated to produce the unit fee.

The units in the study column show how many patients the trainee saw for each item of service out of the 100 consecutive patients studied. This number multiplied by $3439 / 100$ (total patients for the year divided by number of patients in the study) gives the number of units in one year. The units in one year multiplied by the unit fee gives the total earned in one year by the trainee for each item of service: $£ 8627.96$.

The sum of trainer's grant, capitation fees, child health surveillance, and item of service fees was
Edinburgh EH9 1NH Peter A U Twiddy, general practice trainee

BMF 1993;307:1587-8

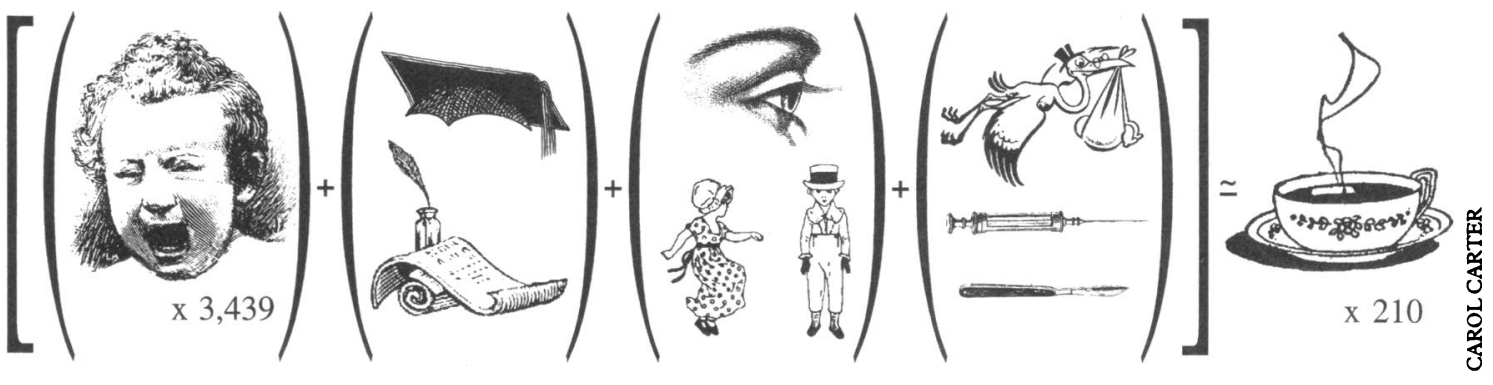


$£ 31$ 353.66. This is the sum earned for the practice by the trainee.

On most days the trainee had a midmorning break, when he drank a cup of coffee provided by the practice. The trainee drank about 210 cups of coffee in one year. A $300 \mathrm{~g}$ jar of coffee makes 165 cups at a cost of $£ 3.85$; 210 cups of coffee will have cost $£ 4$.89. The trainee added $25 \mathrm{ml}$ of milk to each cup, a total of 9.2 pints of milk over the year at a cost of $£ 3.33$. The total cost of the trainee to the practice was $£ 8.22$.

The net financial benefit to the practice of the trainee was $£ 31345.44$.

\section{Discussion}

This study shows that trainees are a considerable financial benefit to a practice: "worth their weight in gold," you might say. My trainer has often commented on my gold-like qualities (the Oxford English Dictionary defines gold as a dense, inert element that is easily malleable and of little practical value).

It may be argued that trainees do work that would otherwise be done by the partners, so there are no financial benefits apart from the trainer's fee. The benefit therefore is of a decreased workload. The truth is probably between the two extremes.

It may also be argued that trainees cannot be worth their weight in gold: at the present market value of $£ 247.44$ per Troy ounce, a $70 \mathrm{~kg}$ trainee would be worth over $£ 450000$. An occasional jar of coffee is a worthwhile investment. The practice that wishes to maximise its income should choose a trainee who takes coffee black.

\section{Urine culture in the diagnosis of colovesical fistula}

\section{A Sandison, P A Jones}

Colovesical fistulas are uncommon. Investigation does not always confirm or define the underlying aetiology. We report a case in which the patient had cultured his urine and so presented with a proved enterovesical fistula.

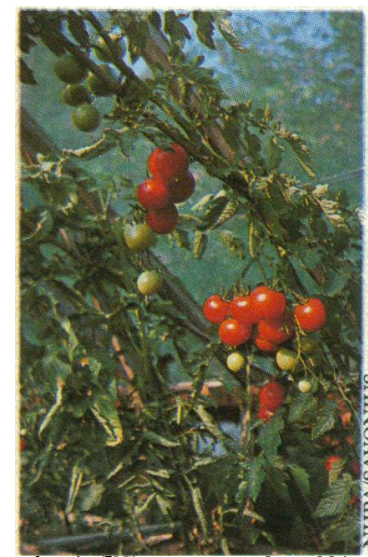

A retired nurseryman cultured his urine-with unique results

Maidstone Hospital, Maidstone, Kent ME16 9QQ

A Sandison, surgical registrar

P A Jones, consultant surgeon

Correspondence to:

Mr A Sandison

BMF 1993;307:1588

\section{Case report}

A 72 year old retired nurseryman presented with a one month history of passing brown urine and debris per urethra. On direct questioning he admitted pneumaturia. On examining his urine he noticed what he thought were tomato seeds. Realising this would imply a communication between his bowel and bladder he was anxious to determine whether these really were tomato seeds. He planted them in sterile potting medium and grew a tomato plant (figure). During this time his bowels were open regularly with no recent change and no bleeding and he was otherwise asymptomatic. His history included divertransurethral resection of the prostate in 1991.

A diagnosis of colovesical fistula was made. A barium enema showed partial obstruction of the sigmoid colon with a soft tissue mass in the pelvis reported to suggest carcinoma rather than diverticular disease, but computed tomography clearly showed a fistula between the sigmoid colon and the bladder, which suggested that the cause was diverticular disease and not tumour. An intravenous urogram showed normal results, and diagnostic urethrocystoscopy showed gross generalised cystitis with faecal debris emerging through a defect in the posterior bladder wall.

Laparotomy confirmed a large diverticular mass adherent to the bladder and the pelvic wall. A one stage sigmoid colectomy with stapled anastomosis was performed and a $1.5 \mathrm{~cm}$ bladder defect closed with interrupted Vicryl. An omental graft was interposed between the bladder and colon, where it was sutured to prevent dislodgement. The patient made an uneventful recovery, was discharged home after eight days, and has remained free of symptoms. Histology confirmed diverticular disease only. ticular disease shown on barium enema in 1990 and a

\section{Comment}

Enterovesical fistulas are uncommon, accounting for approximately one in 3000 admissions to hospital Colovesical fistulas make up most of these. The diagnosis is essentially a clinical one, dependent on eliciting the classic history of pneumaturia or of faecaluria, which occur in $67 \%$ and $45 \%$ of patients respectively. ${ }^{1}$ Culture of the urine in such patients usually results in either a pure growth or a mixed growth of bowel organisms. More specific urine tests to confirm the presence of a fistula include the oral administration of charcoal followed by its detection in the urine, with a success rate of $50-100 \%$; the Bourne test, in which the urine is subjected to $x$ rays after barium enema to detect the presence of barium in the urine; and simple microscopy to detect cellulose fibres. Culture of the urine in sterile potting medium, however, has not been described previously.

Traditionally, confirmation of the diagnosis of colovesical fistula has rested on a combination of cystoscopy and barium enema examination. Cystoscopy shows highly suggestive abnormalities in $90 \%$ of cases and the fistula may be seen in a third of cases. Biopsies should also be taken to exclude a urological malignancy as the cause of the fistula. Barium enema shows a fistula in only a third of cases but is helpful in establishing the underlying colorectal disease. This is important, because if colonic cancer is suspected the bladder fistulas should be resected en bloc, whereas with fistulas caused by diverticulitis the bladder defect may be left or repaired after colectomy.

More recently, computed tomography has been proposed as an effective diagnostic investigation; it has a diagnostic accuracy in excess of $90 \%$. This is based on its ability to detect small amounts of free air in the bladder (other causes of this such as catheterisation must of course be excluded). Direct visualisation of the fistula, as occurred in our case, is seen in only $24 \%$ of scans.

1 Kirsh GM, Hampel N, Shuck JM, Resnick MI. Diagnosis and managemen of vesicoenteric fistulas. Surg Gynecol Obstet 1991;173:91-7. 